\title{
ANALISIS KERAPATAN EKOSISTEM MANGROVE DI PULAU PANIKIANG DAN DESA TONGKE-TONGKE SULAWESI SELATAN
}

\author{
Andi Nur Samsi ${ }^{1 *}$, Sharifuddin Bin Andy Omar², Andi Niartiningsih ${ }^{3}$ \\ ${ }^{1}$ Prodi Pendidikan Biologi STKIP Pembangunan Indonesia Makassar \\ ${ }^{2}$ Jurusan Perikanan FIKP Universitas Hasanuddin Makassar \\ ${ }^{3}$ Jurusan Ilmu Kelautan FIKP Universitas Hasanuddin Makassar
}

*E-mail: andinursamsi89@gmail.com

\begin{abstract}
The mangrove ecosystem has different density levels per location. It can be influenced by environmental factors or because of human assistance. This research was conducted in Tongke-tongke Village, Sinjai Regency and Pannikiang Island, Barru District. Observations were conducted on three groups, namely groups of trees, stakes, and seedlings. Tree group used plot size $10 \mathrm{~m} \times 10 \mathrm{~m}$, stakes group used plot size $5 \mathrm{~m} \times 5 \mathrm{~m}$, and the group of seedlings used plot size $1 \mathrm{~m} \times 1 \mathrm{~m}$. The result of tree group density will be compared with the standard criteria of mangrove damage of the Minister of Environment to know the criteria and the level of density. The mangrove ecosystem in Tongke-tongke village is overgrown by Rhizophora mucronata and Avicennia sp. and is dominated by $R$. mucronata with very dense density. In the tree group, $R$. mucronata has a density of 8020 Ind $\mathrm{Ha}^{-1}$. The mangrove ecosystem in Pannikiang Island is overgrown with Rhizophora apiculata, Rhizophora stylosa, Sonneratia alba, Aegiceras floridum, Ceriops tagal, Avicennia sp., Excoearia agallocha, and Lumnitzera racemosa and has a rare and moderate density. In the tree group, the highest density in $C$. tagal with a density of 1270 Ind $\mathrm{Ha}^{-1}$ and indicated moderate density. Competition is always there in the ecosystem. The species of this ecosystem is fighting for space and nutrients. Therefore, competition can determine the density of plants in it.
\end{abstract}

Keywords: Density; Mangrove Ecosystem; Panikiang Island; Tongke-tongke.

\section{PENDAHULUAN}

Ekosistem mangrove merupakan ekosistem yang sangat bernilai tinggi bagi kehidupan manusia dan kehidupan biota yang ada di dalamnya yang terletak di sekitar pesisir. Mangrove itu sendiri dipengaruhi oleh banyak hal seperti gelombang, pasang surut, salinitas, suhu, dan kegiatan manusia. Kegiatan manusia ini dapat berdampak negatif ataupun berdampak positif. Berdampak negatif jika manusia mengeksploitasi mangrove secara berlebihan. Berdampak positif jika manusia membantu atau melakukan penanaman bakau.

Kegiatan manusia dapat mempengaruhi kerapatan mangrove (Rakotomavo dan Fromard, 2010). Selain itu, kompetisi juga akan mempengaruhi keberlangsungan individu. Kompetisi selalu ada dalam ekosistem. kompetisi itu sendiri merupakan persaingan individu dalam memperebutkan sumberdaya alam yang sama dengan jumlah yang terbatas (Lang dan Benbow, 2013). Hal inilah yang akan menentukan keberlangsungan hidupnya dan dapat diukur dengan kerapatannya. Dengan demikian ada banyak hal yang mempengaruhi kerapatan ekosistem mangrove.
Ekosistem mangrove yang ada di Pulau Panikiang merupakan ekosistem alami sedangkan ekosistem di Desa Tongke-tongke merupakan ekosistem hasil rehabilitasi. Perbedaan inilah yang melatarbelakangi penelitian ini. Penelitian ini bertujuan menggambarkan kondisi kerapatan ekosistem Pulau Pannikiang dan Desa Tongketongke.

\section{METODOLOGI PENELITIAN}

Penelitian dilaksanakan dari bulan Juli 2014. Lokasi penelitian pada areal mangrove di Desa Tongke-tongke, Kecamatan Sinjai Timur, Kabupaten Sinjai dan mangrove yang terletak di Pulau Panikiang, Kabupaten Barru, Sulawesi Selatan.

\section{Sampel penelitian}

Sampel dari penelitian ini adalah pohon, pancang, dan semai yang ada pada ekosistem mangrove di Pulau Panikiang dan ekosistem mangrove di Desa Tongke-tongke.

\section{Instrumen penelitian}

Bahan penelitian adalah tumbuhan mangrove (kelompok pohon, pancang, dan semai). Posisi 
stasiun di lokasi penelitian ditentukan dengan alat bantu GPS (Garmin GPSMAP 76 CSX). Batas-batas plot di stasiun penelitian menggunakan tali plastik. Hasil pengukuran dicatat dalam daftar isian yang telah disiapkan sebelumnya.

Lokasi penelitian di Pulau Panikiang yaitu $4^{\circ} 20^{\prime 2} 2.08^{\prime \prime S}$ dan 119³6'11.69"E sedangkan di Desa Tongke-tongke yaitu $5^{\circ} 9^{\prime} 4.28 " S$ dan 12016'24.12"E.

Pada setiap stasiun diletakkan plot berukuran $10 \mathrm{~m} \mathrm{x} 10 \mathrm{~m}$ masing-masing dua buah untuk pengamatan mangrove tingkat pohon, anakan, dan semaian. Jarak antar plot 10 meter. Sampling dilakukan enam kali pada titik pengamatan yang berbeda. Pengamatan dilakukan terhadap strata mangrove meliputi strata pohon, strata pancang dan strata semai. Pengamatan mangrove pada strata pohon meliputi transek dengan ukuran 10 x $10 \mathrm{~m}$. Kriteria pohon mangrove adalah tegakan dengan ukuran diameter batang $\geq 4 \mathrm{~cm}$. Pengamatan strata pancang mangrove meliputi transek dengan ukuran 5 x $5 \mathrm{~m}$ yang merupakan bagian dari transek pada pengamatan pohon. Kriteria mangrove pada strata pancang adalah tegakan dengan ukuran tinggi $>1 \mathrm{~m}$ dengan diameter batang $>1 \mathrm{~cm}$ dan $<4 \mathrm{~cm}$. Sementara untuk tingkatan semai, pengamatan dilakukan pada transek dengan ukuran $1 \mathrm{x} 1 \mathrm{~m}$ yang merupakan bagian dari transek pada pengamatan pohon. Kriteria mangrove strata semai adalah tegakan mangrove dengan ukuran diameter batang $\leq$ $1 \mathrm{~cm}$ dan tinggi $\leq 1 \mathrm{~m}$ (Hastuti et al., 2013). Identifikasi jenis mangrove mengacu ke panduan oleh Rusila Noor et al. (1999) dan Kitamura et al. (1997).

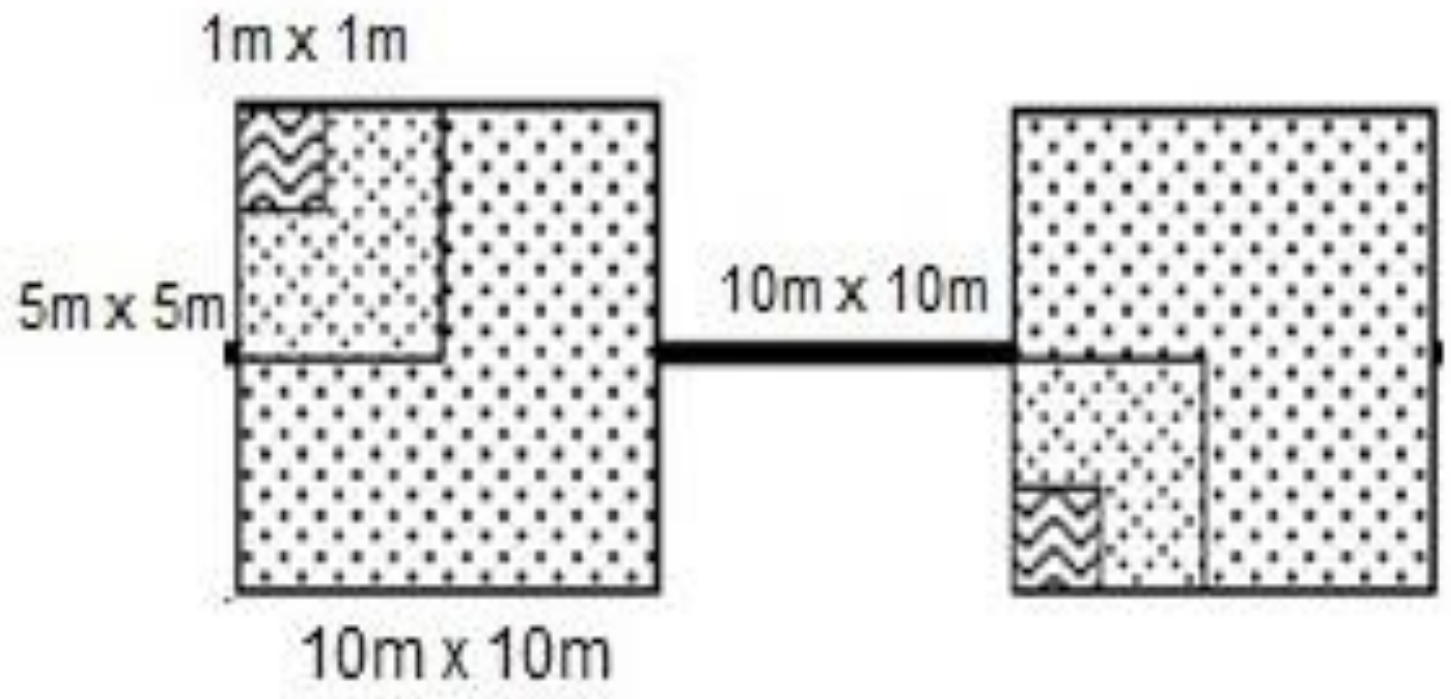

Gambar 1. Desain plot yang digunakan.

\section{Analisis data}

Kerapatan jenis adalah jumlah tegakan mangrove per satuan unit area, dengan rumus sebagai berikut (Brower et al., 1990):

$$
D_{m}=\frac{n_{i}}{A}
$$

Keterangan: $D_{m}=$ kerapatan mangrove jenis ke-i (ind $\mathrm{m}^{-2}$ ), $\mathrm{n}_{\mathrm{i}}=$ jumlah total individu mangrove jenis ke-i, $\mathrm{A}=$ luas total daerah tempat pengambilan sampel, yaitu luas plot $(10 \mathrm{~m} \times 10 \mathrm{~m})$ dikalikan dengan jumlah ulangan $\left(\mathrm{m}^{2}\right)$.

\section{HASIL DAN PEMBAHASAN}

\section{A. Hasil}

Hasil penelitian yang diperoleh (Tabel 1) di kelompok pohon di Pulau Pannikiang dengan kerapatan terendah pada Aegiceras floridum dengan kerapatan 0,002 ind $\mathrm{m}^{-2}$ atau 20 ind $\mathrm{Ha}^{-1}$ dan kerapatan tertinggi pada Ceriops tagal dengan kerapatan 0,127 ind $\mathrm{m}^{-2}$ atau 1270 ind $\mathrm{Ha}^{-1}$. Kelompok pohon di Desa Tongke-tongke dengan kerapatan terendah pada Avicennia sp. 0,002 ind m 2 atau 20 ind $\mathrm{Ha}^{-1}$ dan kerapatan tertinggi pada Rhizophora mucronata 0,802 ind $\mathrm{m}^{-2}$ atau 8020 ind $\mathrm{Ha}^{-1}$. Avicennia sp. dan $R$. mucronata merupakan spesies yang ditemukan di desa Tongke-tongke pada kelompok pohon. 
Tabel 1. Kerapatan pohon, pancang, dan semai pada ekosistem mangrove di Pulau Pannikiang dan Desa Tongke-tongke

\begin{tabular}{|c|c|c|c|c|c|}
\hline \multirow[b]{2}{*}{ Kelompok } & \multirow[b]{2}{*}{ Spesies } & \multicolumn{2}{|c|}{ Pulau Pannikiang } & \multicolumn{2}{|c|}{ Desa Tongke-Tongke } \\
\hline & & Ind $\mathrm{m}^{-2}$ & $\begin{array}{c}\text { Tingkat } \\
\text { Kerapatan }\end{array}$ & Ind $\mathrm{m}^{-2}$ & $\begin{array}{c}\text { Tingkat } \\
\text { Kerapatan }\end{array}$ \\
\hline \multirow[t]{9}{*}{ Pohon } & Rhizophora apiculata & 0,038 & Jarang & - & - \\
\hline & Rhizophora stylosa & 0,072 & Jarang & - & - \\
\hline & Sonneratia alba & 0,015 & Jarang & - & - \\
\hline & Aegiceras floridum & 0,002 & Jarang & - & - \\
\hline & Ceriops tagal & 0,127 & Sedang & - & - \\
\hline & Avicennia sp. & 0,052 & Jarang & 0,002 & Jarang \\
\hline & Excoearia agallocha & 0,008 & Jarang & - & - \\
\hline & Lumnitzera racemosa & 0,003 & Jarang & - & - \\
\hline & $\begin{array}{l}\text { Rhizophora } \\
\text { mucronata }\end{array}$ & - & - & 0,802 & Sangat padat \\
\hline \multirow[t]{6}{*}{ Pancang } & Rhizophora apiculata & 0,033 & Jarang & - & - \\
\hline & Ceriops tagal & 0,273 & Sangat padat & - & - \\
\hline & Rhizophora stylosa & 0,273 & Sangat padat & - & - \\
\hline & Lumnitzera racemosa & 0,013 & Jarang & - & - \\
\hline & Avicennia sp. & 0,013 & Jarang & - & - \\
\hline & Rhizophora mucronata & - & - & 0,467 & Sangat padat \\
\hline \multirow[t]{5}{*}{ Semai } & Rhizophora apiculata & 5,833 & Sangat padat & - & - \\
\hline & Ceriops tagal & 5,833 & Sangat padat & - & - \\
\hline & Rhizophora stylosa & 3,833 & Sangat padat & - & - \\
\hline & Avicennia sp. & 4,167 & Sangat padat & 0,167 & Sangat padat \\
\hline & Rhizophora mucronata & - & - & 21,333 & Sangat padat \\
\hline
\end{tabular}

Kelompok pancang di Pulau Pannikiang dengan kerapatan terendah pada Lumnitzera racemosa dan Avicennia sp. dengan kerapatan 0,013 ind $\mathrm{m}^{-2}$ atau 130 ind $\mathrm{Ha}^{-1}$ dan kerapatan tertinggi pada C. tagal dan Rhizophora stylosa dengan kerapatan 0,273 ind $\mathrm{m}^{-2}$ atau 2730 ind $\mathrm{Ha}^{-1}$. Kelompok pancang di Desa Tongke-tongke memiliki kerapatan 0,467 ind $\mathrm{m}^{-2}$ atau 4670 ind $\mathrm{Ha}^{-1}$ pada $R$. mucronata. $R$. mucronata adalah spesies yang dapat ditemukan di desa Tongke-tongke pada kelompok pancang.

Kelompok semai di Pulau Pannikiang dengan kerapatan terendah pada $R$. stylosa dengan kerapatan 3,833 ind $\mathrm{m}^{-2}$ atau 38330 ind $\mathrm{Ha}^{-1}$ dan kerapatan tertinggi pada $R$. apiculata dan $C$. tagal dengan kerapatan 5,833 ind $\mathrm{m}^{-2}$ atau 58330 ind $\mathrm{Ha}^{-1}$. Kelompok semai di Desa Tongke-tongke dengan kerapatan terendah pada Avicennia sp. dengan kerapatan 0,167 ind $\mathrm{m}^{-2}$ atau 1670 ind $\mathrm{Ha}^{-1}$ dan kerapatan tertinggi pada $R$. mucronata dengan kerapatan 21,333 ind $\mathrm{m}^{-2}$ atau 213300 ind $\mathrm{Ha}^{-1}$. Avicennia sp. dan $R$. mucronata merupakan spesies yang ditemukan di desa Tongke-tongke pada kelompok semai.

\section{B. Pembahasan}

Ekosistem mangrove di Pulau Pannikiang merupakan ekosistem alami yang didiami beberapa spesies seperti $R$. apiculata, $R$. stylosa, S. alba, A. floridum, C. tagal, Avicennia sp., E. agallocha dan $L$. racemosa. Sebaliknya, ekosistem mangrove di Desa Tongke-tongke merupakan ekosistem hasil rehabilitasi sehingga spesies dominannya yaitu $R$. mucronata dan terkadang ditemukan Avicennia sp. yang tumbuh secara alami karena berdampingan dengan area mangrove alami (perbatasan Desa Tongke-tongke dan Samataring).

Hasil yang serupa juga ditemukan oleh Hastuti et al. (2013) yaitu mendapatkan data kerapatan untuk kelompok pohon pada Avicennia antara 600 4700 ind $\mathrm{Ha}^{-1}$ (kerapatan jarang sampai sangat padat), kelompok pancang antara $1867-18000$ ind $\mathrm{Ha}^{-1}$ (kerapatan sangat padat), dan kelompok semai antara 16667 - 150000 ind $\mathrm{Ha}^{-1}$ (kerapatan sangat padat) di wilayah pesisir Semarang dan Demak. Kerapatan untuk kelompok pohon pada Rhizophora antara 1422 - 6517 ind $\mathrm{Ha}^{-1}$ (kerapatan sedang sampai sangat padat), kelompok pancang antara 1600- 13822 ind $\mathrm{Ha}^{-1}$ (kerapatan sangat padat), dan kelompok semai sekitar 22000 - 305556 ind $\mathrm{Ha}^{-1}$ 
(kerapatan sangat padat) di wilayah pesisir Semarang dan Demak. Hasil yang berbeda ditemukan oleh Ulqodry (2008) yaitu hanya menemukan spesies Avicennia marina dan Sonneratia caseolaris di ekosistem mangrove Tanjung Api-api. Kerapatan pohon Avicennia marina antara 167 - 1733 ind $\mathrm{Ha}^{-1}$ (kerapatan jarang sampai sangat padat) dan kerapatan pohon Sonneratia caseolaris antara 0 1333 ind $\mathrm{Ha}^{-1}$ (kerapatan jarang sampai sedang).

Hasil yang sangat berbeda ditemukan oleh Zamroni dan Rohyani (2008) di Teluk Sepi, Lom- bok Barat dan memeroleh delapan spesies mangrove yaitu Rhizophora apiculata, $R$. mucronata, $R$. stylosa, Ceriops tagal, C. decandra, Brugueria sp., Sonneratia alba, dan Aegiceras corniculatum. Ekosistem mangrove ini didominasi oleh $R$. mucronata dan $R$. apiculata. Kerapatan pohon $R$. mucronata terbesar sebanyak 392 ind $\mathrm{Ha}^{-1}$, diikuti $R$. apiculata sebesar 72 ind $\mathrm{Ha}^{-1}$, dan vegetasi lainnya sebesar 16 ind $\mathrm{Ha}^{-1}$ (kerapatan jarang). Selain itu, kriteria baik atau rusaknya sebuah ekosistem dapat dinilai dari kerapatan pohonnya (Tabel 2).

Tabel 2. Kriteria baku kerusakan mangrove

\begin{tabular}{ccc}
\hline Kriteria & Tingkat kerapatan & Kerapatan $($ pohon/Ha) \\
\hline Baik & Sangat padat & $\geq 1500$ \\
& Sedang & $\geq 1000-<1500$ \\
Rusak & Jarang & $<1000$ \\
\hline Sumber: Keputusan Menteri Lingkungan Hidup No.201 Tahun 2004
\end{tabular}

Sumber: Keputusan Menteri Lingkungan Hidup No.201 Tahun 2004.

Jika membandingkan kerapatan spesies penyusun ekosistem mangrove dengan kriteria baku kerusakan mangrove dapat diketahui pada $R$. mucronata di Desa Tongke-tongke baik pada kelompok pohon, pancang, dan semai memiliki kerapatan sangat padat $(\geq 1500$ pohon/Ha) dengan kriteria baik. Hal ini disebabkan masyarakat menjaga ekosistem mangrove di Desa Tongketongke. Ekosistem mangrove di Desa Tongketongke merupakan hasil swadaya masyarakat. Luas hutan mangrove di Desa Tongke-Tongke mencapai 350 Ha dan didominasi jenis Rhizophora mucronata (Setiawan, 2013).

Kerapatan spesies penyusun ekosistem mangrove dengan kriteria baku kerusakan mangrove di Pulau Pannikiang memiliki tingkat kerapatan jarang dan sedang. Pulau Pannikiang ini merupakan tipe ekosistem mangrove alami sehingga spesies penyusunnya tumbuh dan berkembang secara alami tanpa campur tangan manusia. Hal ini yang menyebabkan terkadang ada spesies yang memiliki kerapatan yang rendah. Selain itu, berbeda halnya dengan ekosistem mangrove di Desa Tongke-tongke yang memiliki jarak tanam yang diatur oleh manusia/masyarakat yang menyebabkan dapat tumbuh dengan baik. Lain halnya pada ekosistem mangrove di Pulau Pannikiang ini tidak memiliki jarak tanam/jarak tumbuh yang pasti, bahkan saling berdekatan sehingga banyak yang dapat tumbuh dan bertahan sampai umur tua. Selain itu, hal ini juga mendorong terjadinya kompetisi yang sangat ketat. Inilah yang menyebabkan ada spesies yang dengan kerapatan jarang/kecil. Luas ekosistem mangrove di Pulau Pannikiang ini mencapai 89,01 Hektar atau mencapai 87,45\% lahan di pulau tersebut (Amran et al., 2012).

Kerapatan mangrove di Pulau Pannikiang terdapat mulai jarang, sedang, dan sangat padat sedangkan pada kerapatan mangrove di Desa Tongke-tongke terdapat jarang dan sedang. Kondisi kerapatan mangrove di kedua ekosistem ini mirip. Hal ini juga terbukti dari beberapa faktor lingkungan yang diukur. Suhu di kedua ekosistem ini berkisar $28^{\circ} \mathrm{C}$ sedangkan $\mathrm{pH}$ di kedua ekosistem ini berkisar 7.

Jika ditinjau dari segi salinitas pada kedua ekosistem ini, ekosistem di Pulau Pannikiang berada antara 25,5\% sampai 32\% sedangkan di Desa Tongke-tongke berada $12 \%$ sampai $27 \%$. Perbedaan salinitas ini juga mempengaruhi ukuran populasi mangrove di kedua ekosistem ini.

\section{KESIMPULAN}

Ekosistem mangrove di Desa Tongke-tongke didominasi oleh $R$. mucronata dengan tingkat kerapatan sangat padat. Pada kelompok pohon, $R$. mucronata memiliki kerapatan 8020 Ind $\mathrm{Ha}^{-1}$. Hasil yang mirip juga ditemukan pada ekosistem mangrove di Pulau Pannikiang memiliki tingkat kerapatan mulai dari jarang sampai sangat padat. Pada kelompok pohon, kerapatan tertinggi pada $C$. tagal dengan kerapatan 1270 Ind $\mathrm{Ha}^{-1}$ dan tergolong sedang. Jika ditinjau dari segi spesies penyusun ekosistem, ekosistem di Pulau Pannikiang jauh lebih banyak dibandingkan ekosistem di Desa Tongketongke. 


\section{DAFTAR PUSTAKA}

[1] Amran, M.A., Yasir, I., Hamzah, A., Selamat, M.B., \& Niartiningsih, A.. (2012). Kondisi Ekosistem Mangrove di Pulau Pannikiang, Kabupaten Barru. Abstrak Penelitian Hibah Unggulan Perguruan Tinggi Tahun 2012. Lembaga Penelitian dan Pengabdian Masyarakat (LP2M). Universitas Hasanuddin.

[2] Brower, J.E., J.H. Zar \& C.N. von Ende. (1990). Field and Laboratory Methods for General Ecology. Wm.C. Brown Publishers. Dubuque.

[3] Hastuti, E. D., Anggoro, S., \& Pribadi, R. (2013). Pengaruh Jenis dan Kerapatan Vegetasi Mangrove terhadap Kandungan $\mathrm{Cd}$ dan Cr Sedimen di Wilayah Pesisir Semarang dan Demak.

[4] Keputusan Menteri Lingkungan Hidup No.201 Tahun 2004.

[5] Kitamura, S., Anwar, C., Chaniago, A., \& Baba, S. (1997). Buku Panduan Mangrove di Indonesia - Bali dan Lombok. JICA/ISME/MIC. Bali.
[6] Lang, J. M., \& Benbow, M. E. (2013). Species interactions and competition. Nature Education Knowledge, 4(8).

[7] Rakotomavo, A., \& Fromard, F. (2010). Dynamics of mangrove forests in the Mangoky River delta, Madagascar, under the influence of natural and human factors. Forest Ecology and Management, 259(6), 1161-1169.

[8] Rusila Noor, Y., Khazali, M., \& Suryadiputra, I.N.N. (1999). Panduan Pengenalan Mangrove di Indonesia. PKA/WIIP. Bogor.

[9] Setiawan, H. (2013). Status ekologi hutan mangrove pada berbagai tingkat ketebalan. Jurnal Penelitian Kehutanan Wallacea, 2(2), 104-120.

[10] Ulqodry, T. Z. (2008). Produktifitas Srasah Mangrove dan Potensi Kontribusi Unsur Hara di Perairan Mangrove Tanjung Api-Api Sumatera Selatan. [Tesis]. IPB. Bogor.

[11] Zamroni, Y., \& Rohyani, I. S. (2008). Produksi serasah hutan mangrove di perairan pantai Teluk Sepi, Lombok Barat. Jurnal Biodiversitas, 9(4), 284-287. 